Supporting Information

\title{
Hybrid Integration of Carbon Nanotubes and Transition Metal Dichalcogenides on Cellulose Paper for Highly Sensitive and Extremely Deformable Chemical Sensor
}

Woo Sung Lee and Jungwook Choi*

School of Mechanical Engineering, Yeungnam University

280 Daehak-ro, Gyeongsan, Gyeongbuk 38541, Republic of Korea

*Email: jwc@yu.ac.kr

\section{Contents:}

1. TEM images of multiwalled CNT and nanolayered $\mathrm{WS}_{2}$ (Figure S1)

2. UV-visible absorption spectra of $\mathrm{WS}_{2}$ and multiwalled CNT dispersions (Figure $\mathrm{S} 2$ )

3. SEM images of pristine and CNT-coated cellulose paper (Figure S3)

4. Electrical characterizations of $\mathrm{CNT}-\mathrm{WS}_{2}$-cellulose with respect to number of coatings (Figure S4, S5, S6)

5. Improvement of sensing response by $\mathrm{WS}_{2}$ functionalization (Figure $\mathrm{S} 7, \mathrm{~S} 8, \mathrm{~S} 9$ )

6. Comparison of main performance parameters with those of other nanomaterial-based flexible $\mathrm{NO}_{2}$ sensors (Table $\mathrm{S} 1$ )

7. Preparation and sensing responses of CNT-MoS 2 -coated cellulose paper (Figure S10)

8. Temperature coefficient of resistance of CNT-WS 2 -cellulose (Figure S11)

9. Room-temperature $\mathrm{NO}_{2}$ sensing and UV assisted recovery (Figure $\mathrm{S} 12$ )

10. References 


\section{TEM images of multiwalled CNT and nanolayered $\mathrm{WS}_{2}$}

a

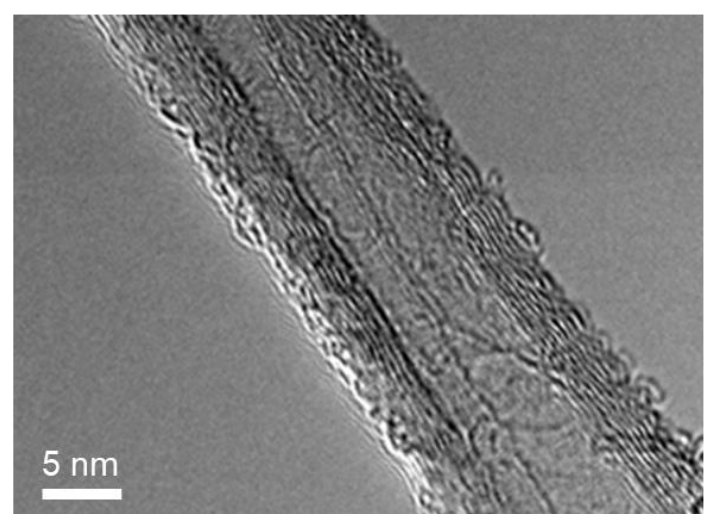

b

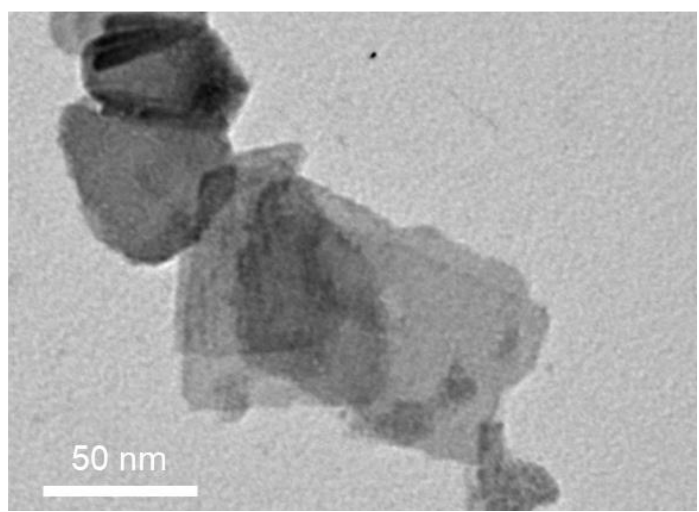

Figure S1. (a) TEM image of multiwalled CNT having an outer diameter of $\sim 15 \mathrm{~nm}$. (b) TEM image of $\mathrm{WS}_{2}$ nanolayers (typically two to three layers) used for functionalizing CNTs to improve the chemical sensitivity. 
2. UV-visible absorption spectra of $\mathrm{WS}_{2}$ and multiwalled CNT dispersions

a
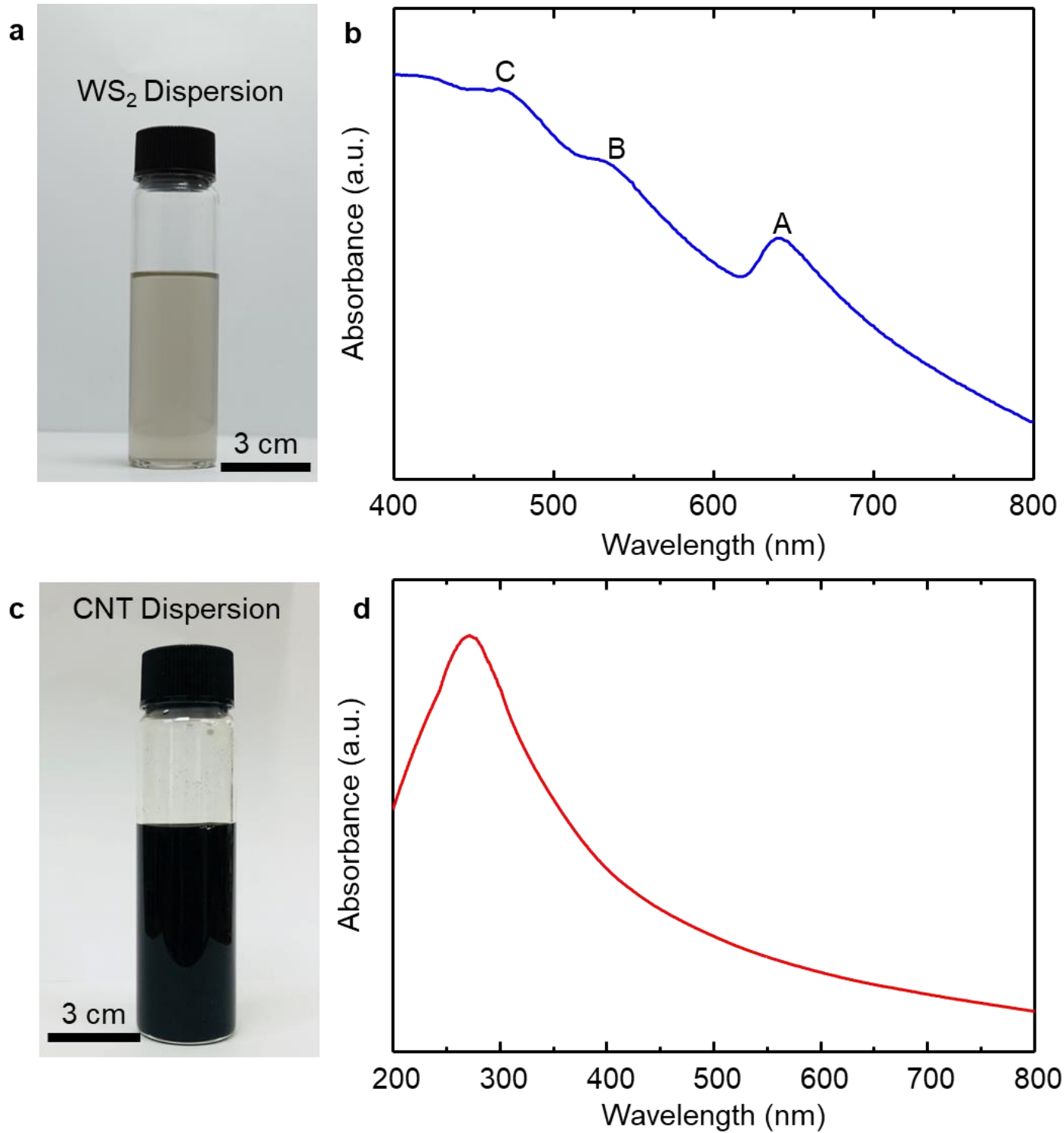

Figure S2. (a) Photograph of $\mathrm{WS}_{2}$ dispersion in DMF with concentration of $\sim 0.2 \mathrm{mg} \mathrm{mL} \mathrm{mL}^{-1}$. (b) Absorption spectrum of $\mathrm{WS}_{2}$ dispersion showing distinctive excitonic signatures at 463 (2.68), 538 (2.30), and $642 \mathrm{~nm}(1.93 \mathrm{eV})$. (c) Photograph of CNT dispersion in DMF with concentration of $\sim 2 \mathrm{mg} \mathrm{mL}^{-1}$. (d) Absorption spectrum of CNT dispersion. 


\section{SEM images of pristine and CNT-coated cellulose paper}

a
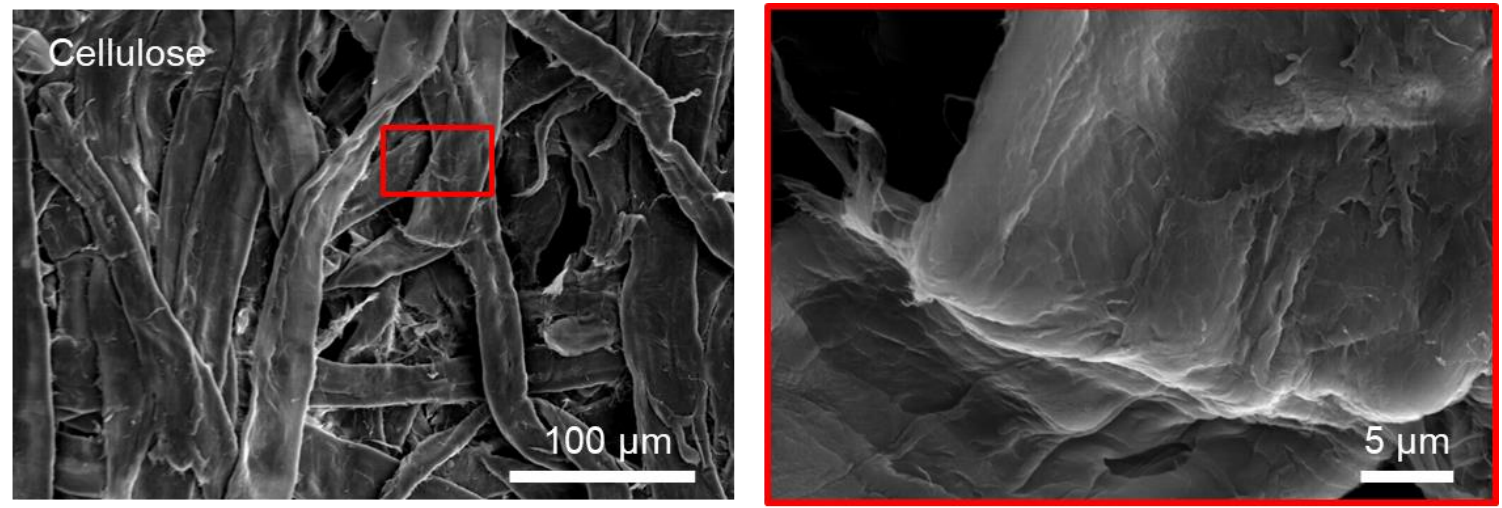

b
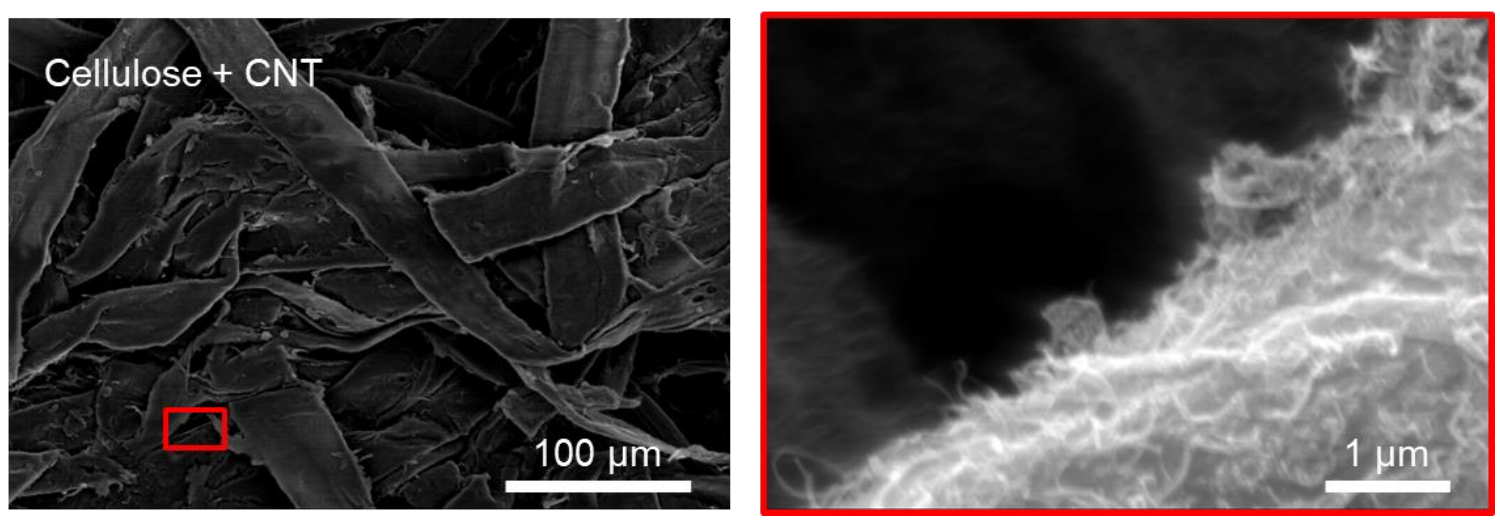

Figure S3. SEM images of (a) pristine cellulose paper and (b) CNT-coated cellulose paper. Microscale fibrous cellulose structures are maintained without significant changes even after multiple CNT coatings. The CNTs form a percolation network on the surfaces of the cellulose microfibers. Right panels in (a) and (b) show enlarged views of the red box in the corresponding left panels. 


\section{Electrical characterization of CNT-WS 2 -cellulose with respect to number of coatings}
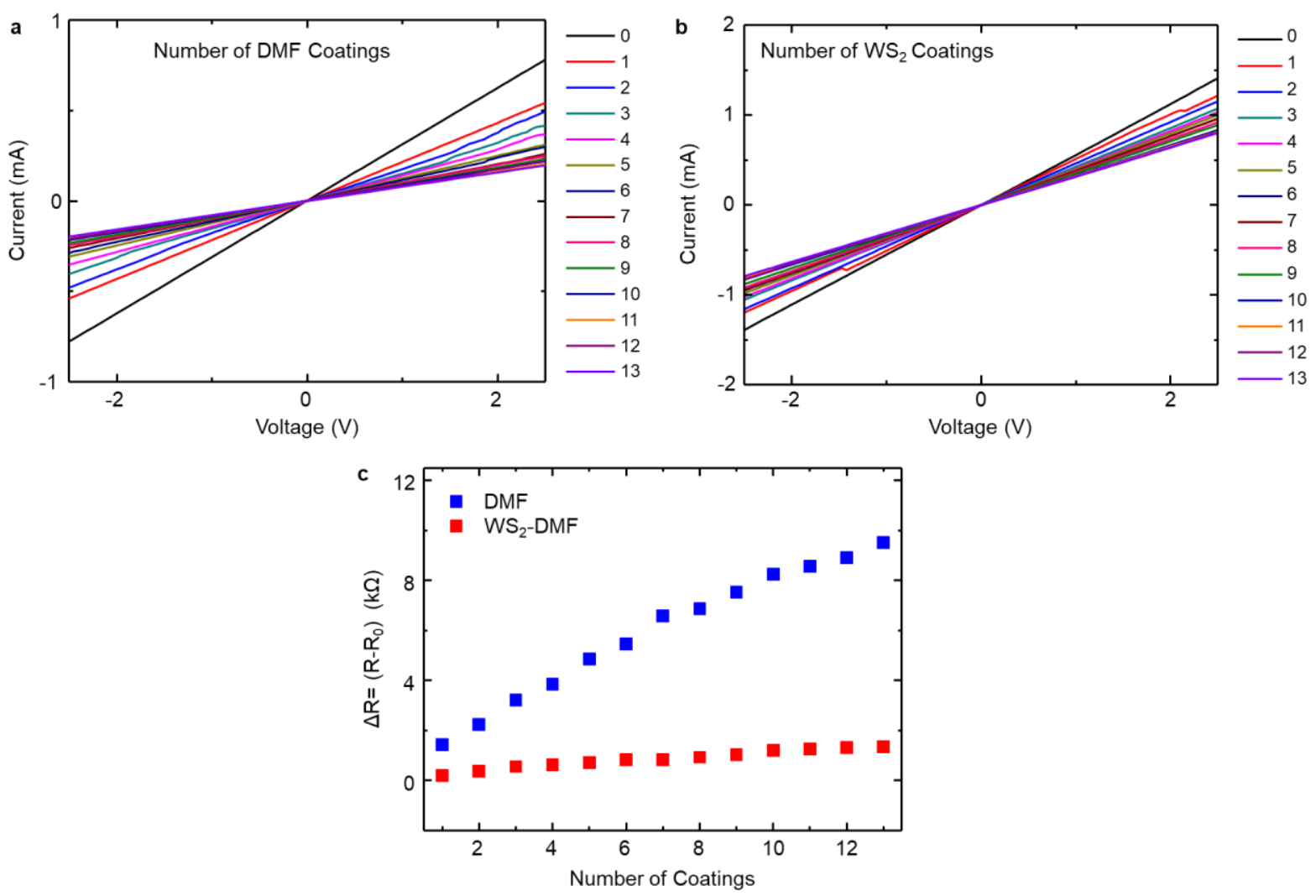

Figure S4. (a) $I-V$ curves of CNT-coated cellulose paper versus number of DMF immersions, measured as a control experiment. The DMF, which is used as a solvent to disperse $\mathrm{WS}_{2}$, increases the resistance of the CNTs. The reason could be interaction between CNTs and methyl group in DMF, which could change the carrier concentration in CNTs by charge transfer. ${ }^{1,2}$ (b) $I-V$ curves of CNT-coated cellulose paper for various numbers of $\mathrm{WS}_{2}$ coatings. Although DMF significantly increases the resistance of the CNTs, as shown in (a), the addition of $\mathrm{WS}_{2}$ suppresses the increasing trend of the resistance, suggesting that the locally deposited $\mathrm{WS}_{2}$ contributes to the decrease in the resistance of the CNTs. (c) Characterization of resistance increase of CNT-coated cellulose paper after the interaction with DMF and $\mathrm{WS}_{2}$-dispersed DMF. The differences originate from the presence of $\mathrm{WS}_{2}$. Thus, the influence of DMF on the resistance can be ruled out. The resistance decrease of the CNTs resulting solely from the $\mathrm{WS}_{2}$ coating is characterized and presented in Figure $3 \mathrm{~b}$ of the main text. 


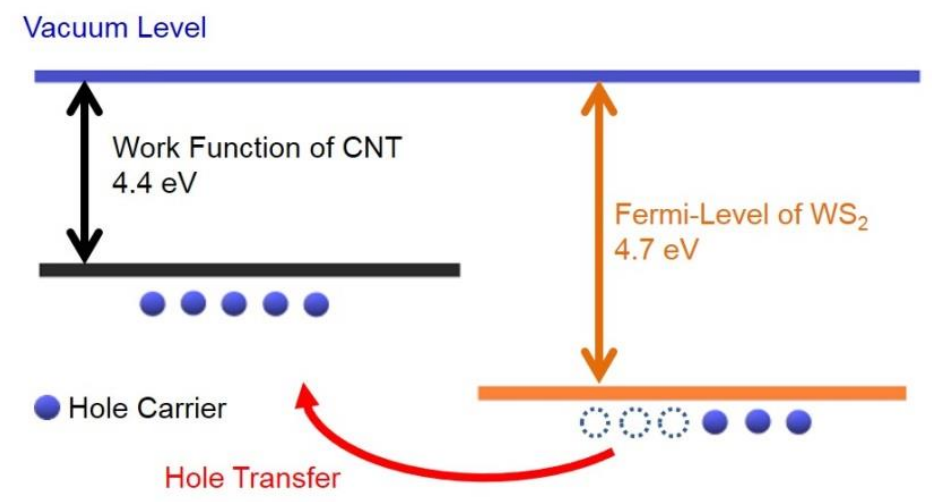

Figure S5. Energy band diagram of multiwalled CNTs and $\mathrm{WS}_{2}$. Both CNTs and $\mathrm{WS}_{2}$ behave as a p-type when they are expose to ambient air owing to physisorbed oxygen molecules, which take electrons from the CNTs and $\mathrm{WS}_{2}{ }^{3,4}$ At their interface, the difference between the work function of CNTs $(4.4 \mathrm{eV})^{5}$ and the Fermi level of $\mathrm{WS}_{2}(4.7 \mathrm{eV})^{6}$ results in hole transfer from $\mathrm{WS}_{2}$ to the CNTs, which increases the carrier concentration and ultimately decreases the resistance of the CNTs.

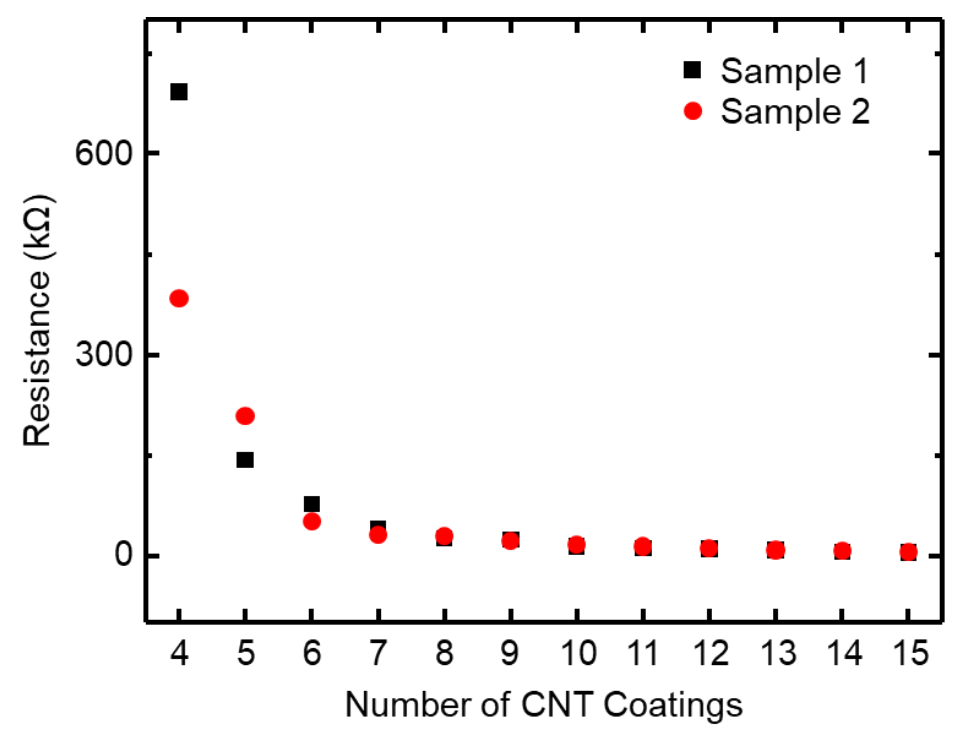

Figure S6. Reproducibility of CNT coating process. As the number of CNT coatings increases, the resistance variation between the two cellulose papers becomes negligible, showing the reproducibility of the sample preparation process. 


\section{Improvement of sensing response by $\mathrm{WS}_{2}$ functionalization}
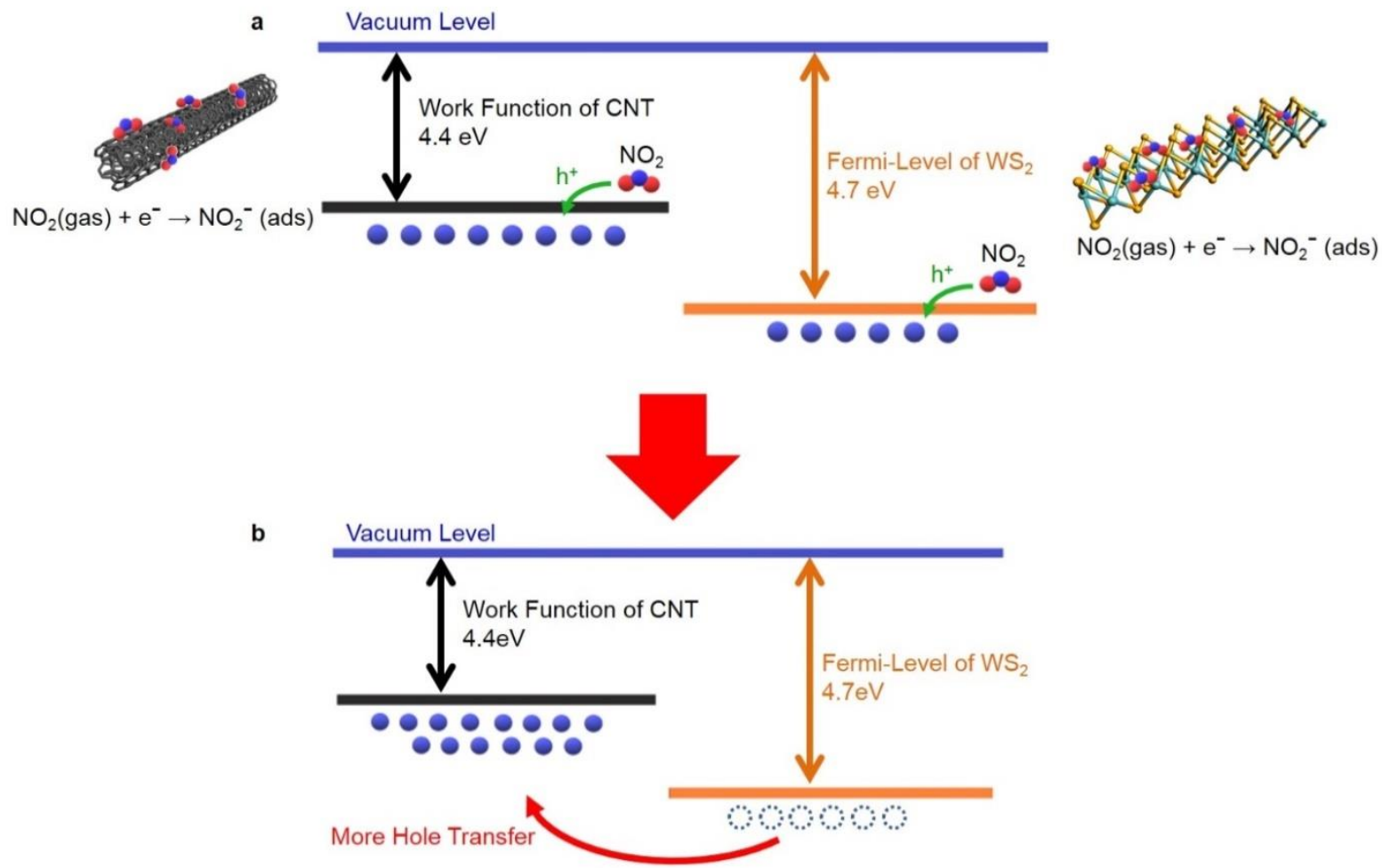

Figure S7. Energy band diagram of multiwalled CNTs and $\mathrm{WS}_{2}$ upon exposure to $\mathrm{NO}_{2}$ molecules. (a) $\mathrm{NO}_{2}$ molecules withdraw electrons from both the CNTs and $\mathrm{WS}_{2}$ when they are adsorbed on their surfaces. ${ }^{7-9}$ Therefore, the hole concentration in the CNTs and $\mathrm{WS}_{2}$ increases compared to that in pure air. (b) The energy level difference transfers the hole carriers generated by $\mathrm{NO}_{2}$ adsorption from $\mathrm{WS}_{2}$ to the CNTs. Thus, the hole concentration in the CNTs increases further, resulting in a larger change in the resistance than the $\mathrm{NO}_{2}$ response of CNTs alone. Note that the $\mathrm{WS}_{2}$ nanolayers are locally deposited on the CNT percolation network, which does not form an electrical pathway, as shown in Figure $2 b$. 

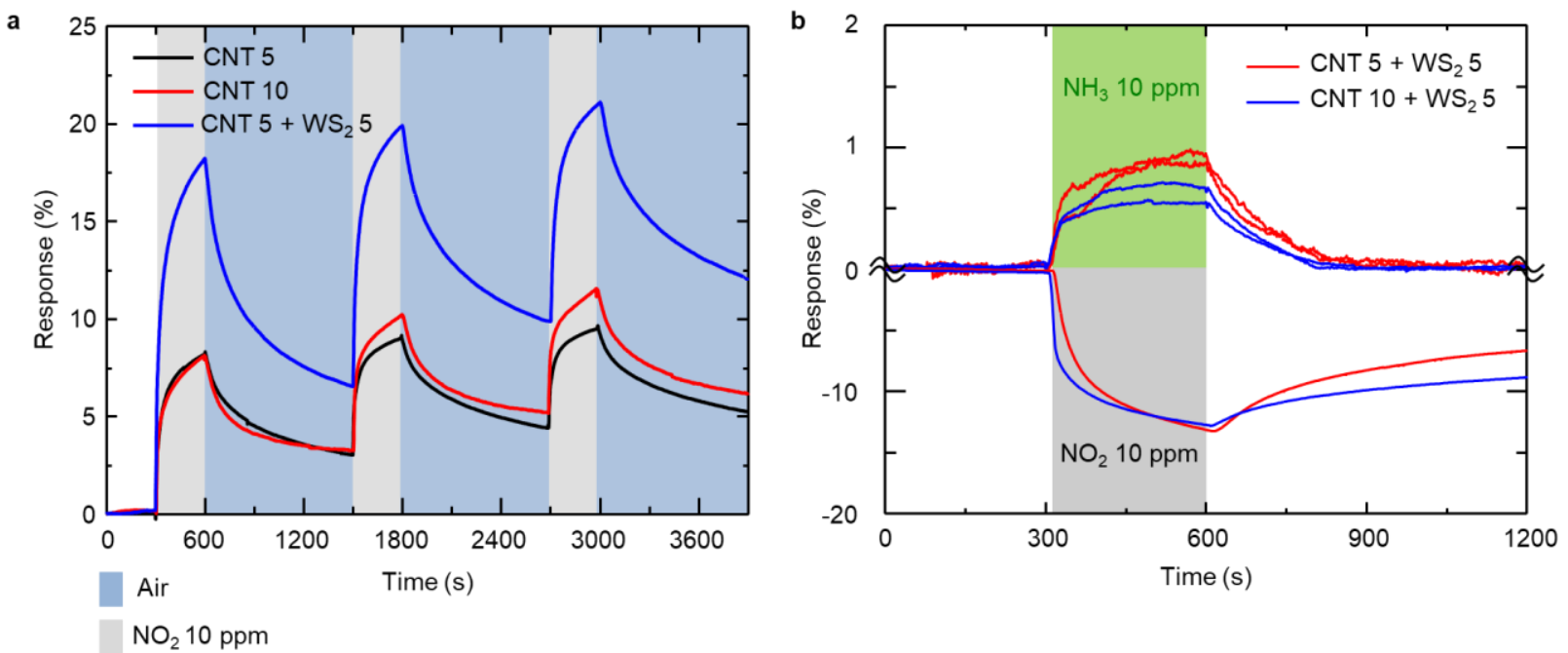

Figure S8. (a) $\mathrm{NO}_{2}$ response of sensors prepared with $5 \mathrm{CNT}$ coatings, $10 \mathrm{CNT}$ coatings, and 5 CNT coatings with an additional $5 \mathrm{WS}_{2}$ coatings. All the experimental conditions, such as the $\mathrm{NO}_{2}$ concentration $(10 \mathrm{ppm})$ and flow rate, are identical except for the number of nanomaterial coatings. Increasing the number of CNT coatings does not further enhance the $\mathrm{NO}_{2}$ sensing response (black and red curves). However, the addition of $\mathrm{WS}_{2}$ significantly improves the response, by over $220 \%$, experimentally demonstrating the utility of $\mathrm{WS}_{2}$ functionalization. (b) $10 \mathrm{ppm} \mathrm{NO}$ and $\mathrm{NH}_{3}$ sensing responses measured by two sets of sensors with different number of CNTs coating. Our sensor shows highly reproducible sensing responses toward both $\mathrm{NO}_{2}$ and $\mathrm{NH}_{3}$.

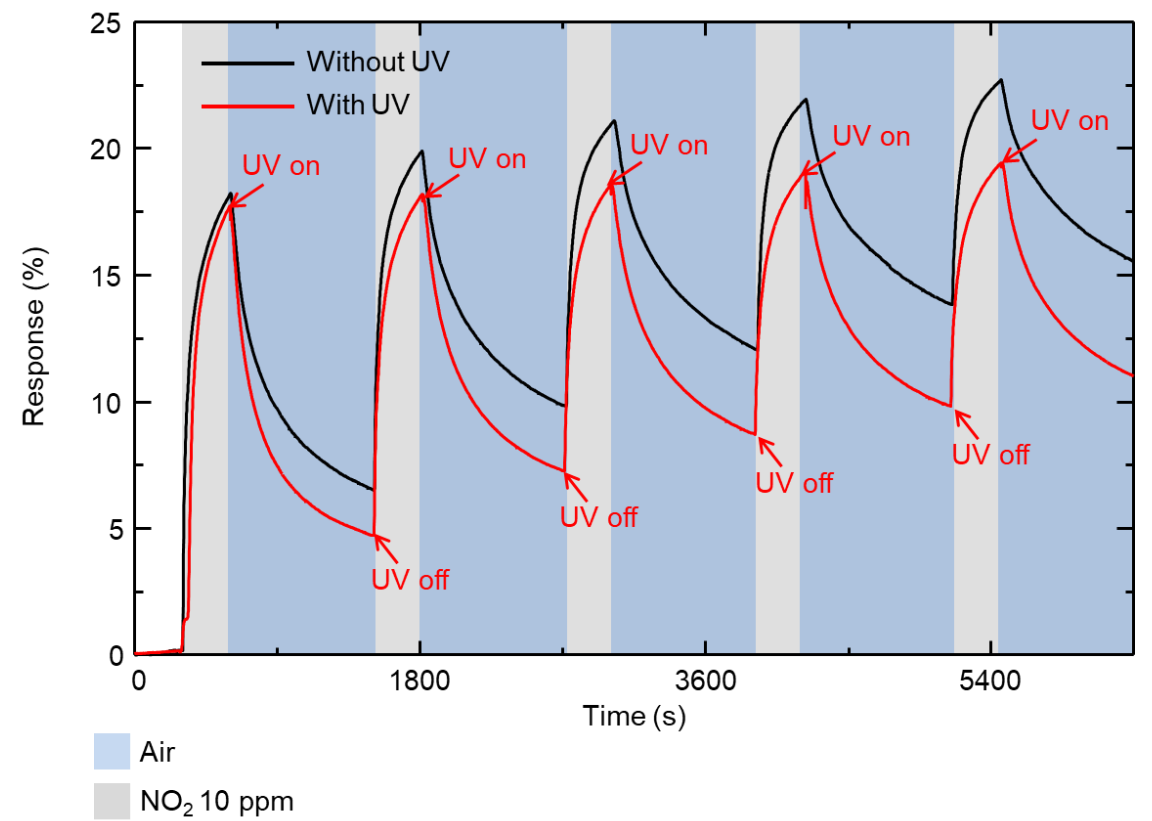

Figure S9. Improved $\mathrm{NO}_{2}$ desorption of CNT-WS 2 hybrid obtained by UV (254 nm) irradiation during recovery cycles. 


\section{Comparison of main performance parameters with those of other nanomaterial-based flexible $\mathrm{NO}_{2}$ sensors}

Table S1. Many outstanding gas sensors have been suggested using carbon nanomaterials with high $\mathrm{NO}_{2}$ sensitivity. ${ }^{10-12}$ In addition, some flexible $\mathrm{NO}_{2}$ sensors show better sensitivity than our device. However, our sensor exhibits better bendability than others, and, importantly, twistable $\mathrm{NO}_{2}$ sensors have not been reported to date. Furthermore, the sensitivity of our sensor is the highest among those of the reported carbon-nanomaterial-based sensors fabricated on a paper substrate. All these features result from the improved sensitivity obtained by $\mathrm{WS}_{2}$ functionalization and the high deformability of the paper substrate.

\begin{tabular}{|c|c|c|c|c|c|c|}
\hline Substrate & $\begin{array}{c}\text { Sensing } \\
\text { Material }\end{array}$ & $\begin{array}{c}\text { Bending } \\
\text { Radius } \\
(\mathrm{mm})\end{array}$ & $\begin{array}{l}\text { Twisting } \\
\text { Angle }\left(^{\circ}\right)\end{array}$ & $\begin{array}{c}\text { Lowest } \mathrm{NO}_{2} \\
\text { Conc. } \\
\text { Measured } \\
(\mathrm{ppm})\end{array}$ & $\begin{array}{l}\text { Sensitivity } \\
\left(\% \text { ppm }^{-1}\right)\end{array}$ & Ref. \\
\hline Paper & $\mathrm{CNT}^{-\mathrm{WS}_{2}}$ & $\begin{array}{c}0.25 \mathrm{~mm} \\
\left(\theta=180^{\circ}\right)\end{array}$ & $1800^{\circ}$ & 0.1 & $\begin{array}{c}4.57(0-2 \mathrm{ppm}) \\
0.84(2-10 \mathrm{ppm})\end{array}$ & $\begin{array}{c}\text { Our } \\
\text { work }\end{array}$ \\
\hline Paper & Graphite & - & - & 0.05 & 1.49 & 13 \\
\hline Paper & Graphene & $\varepsilon=0.5 \%$ & - & 200 & $0.2 *$ & 14 \\
\hline Paper & $\mathrm{CNT}$ & - & - & 40 & $0.3375^{*}$ & 15 \\
\hline Paper & PbS CQDs & $\theta=180^{\circ}$ & - & 0.5 & $\begin{array}{c}9.50 *(0.5-5 \mathrm{ppm}) \\
0.38 *(5-50 \mathrm{ppm}) \\
\end{array}$ & 16 \\
\hline PI & $\mathrm{MoS}_{2}$ & $7 \mathrm{~mm}$ & - & 25 & $2.0^{*}$ & 17 \\
\hline PI & Graphene & $1 \mathrm{~mm}$ & - & 1 & 1.067 & 18 \\
\hline PI & Graphene-Al & $1.9 \mathrm{~mm}$ & - & 1.2 & $0.2875^{*}$ & 19 \\
\hline PI & $\mathrm{MoS}_{2}$-Graphene & $1.9 \mathrm{~mm}$ & - & 1.2 & $3.03 *$ & 20 \\
\hline $\mathrm{PI} / \mathrm{PET}$ & $\begin{array}{c}\text { CNT-Graphene- } \\
\mathrm{WO}_{3}\end{array}$ & $\theta=90^{\circ}$ & - & 1 & $2.5^{*}$ & 21 \\
\hline PET & Ag-S-RGO & $10 \mathrm{~mm}$ & - & 0.5 & $5.6^{*}$ & 22 \\
\hline PET & $\begin{array}{c}\text { MWCNT- } \\
\text { PSSMA-PAH }\end{array}$ & $\theta=60^{\circ}$ & - & 1 & 1.0716 & 23 \\
\hline PET & RGO-MoS $-\mathrm{PtNP}$ & $4 \mathrm{~mm}$ & - & 0.5 & $0.12 *$ & 24 \\
\hline PET & Graphene & $\varepsilon=1.39 \%$ & - & 200 & $4.17^{*}$ & 25 \\
\hline PET & Graphene & $50^{\circ}$ & - & 1 & $2.78 *$ & 26 \\
\hline
\end{tabular}

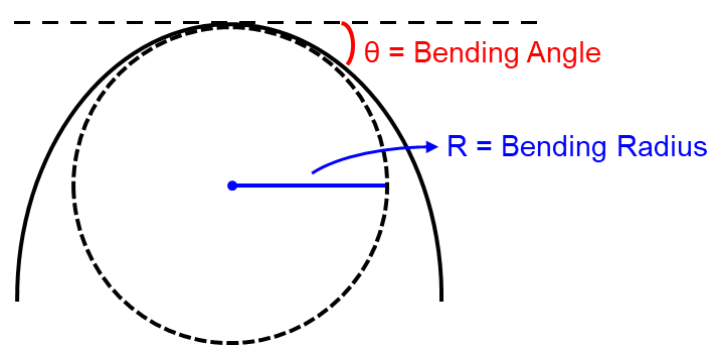

- Asterisk (*) implies the recalculated values according to the definition of sensitivity: $\left(\mid R_{g}-R_{0} / / R_{0}\right) \times 100 / \Delta c$, where $R_{0}$ is the initial resistance, $\mathrm{R}_{\mathrm{g}}$ is the resistance measured in the $\mathrm{NO}_{2}$, and $\Delta \mathrm{c}$ is the change of $\mathrm{NO}_{2}$ concentration.

- Bending radius (R) and angle $(\theta)$ are defined as shown in left. Bending strain is defined as $(\varepsilon=100$ $\times d / 2 r$ ), where $d$ is the thickness of substrate and $r$ is the radius of curvature. ${ }^{27}$ 


\section{Preparation and sensing responses of CNT-MoS 2 -coated cellulose paper}
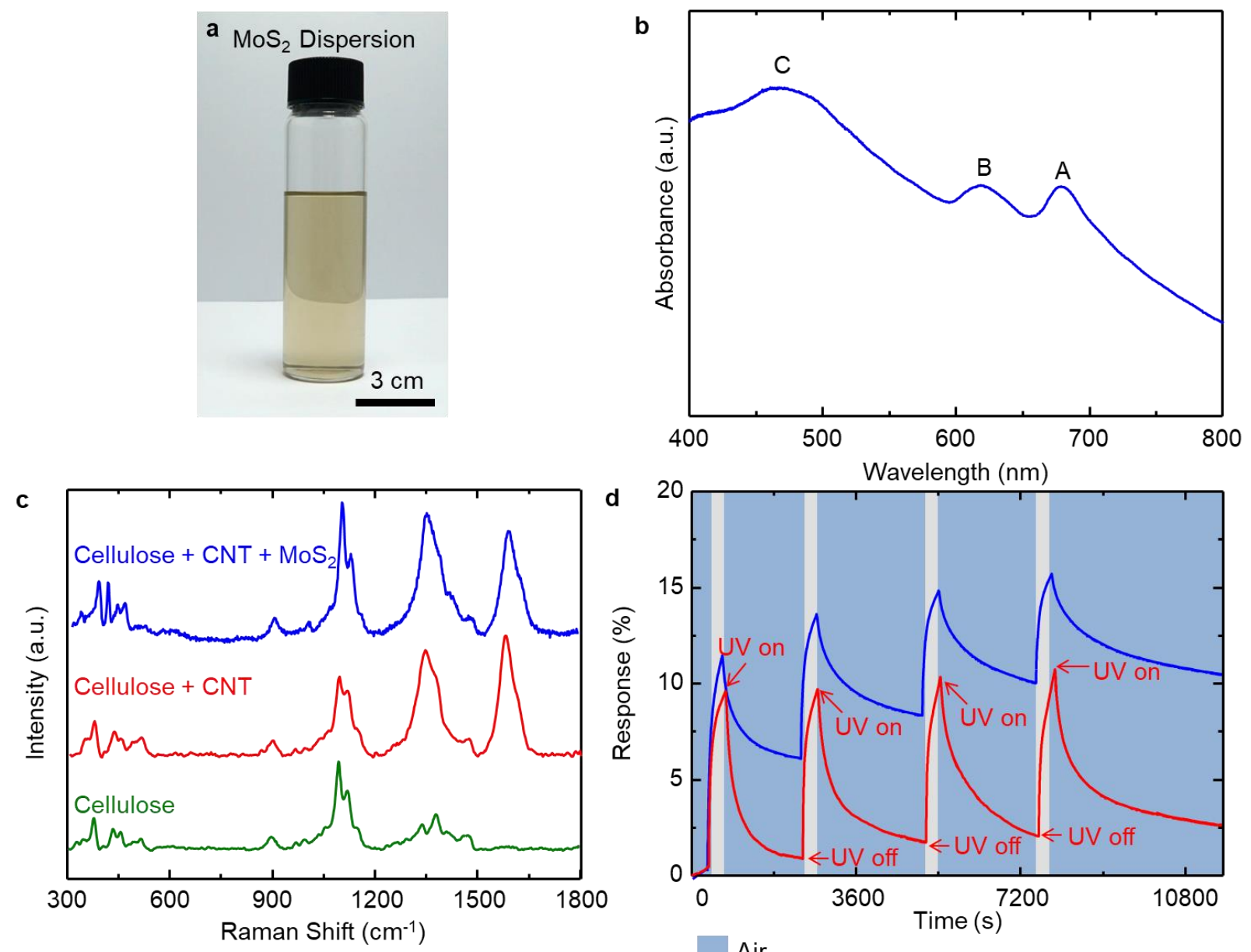

Air

$\mathrm{NO}_{2} 10 \mathrm{ppm}$

Figure S10. Our approach can be extended to functionalize CNTs with other TMDCs such as $\mathrm{MoS}_{2}$ nanolayers. (a) Photograph of $\mathrm{MoS}_{2}$ dispersion in DMF. (b) UV-visible absorption spectrum of $\mathrm{MoS}_{2}$, clearly showing excitonic signatures at 465, 618, and $678 \mathrm{~nm}$. (c) Raman spectra of pristine cellulose (green line), CNT-cellulose (red line), and CNT-MoS 2 -cellulose (blue line). After $\mathrm{MoS}_{2}$ coating, distinctive Raman peaks from $\mathrm{MoS}_{2}$ are observed at $393.2 \mathrm{~cm}^{-1}$ $\left(\mathrm{E}_{2 \mathrm{~g}}^{1}\right)$ and $420.1 \mathrm{~cm}^{-1}\left(\mathrm{~A}_{1 \mathrm{~g}}\right)$. (d) Sensing response of CNT-MoS 2 hybrid to $10 \mathrm{ppm} \mathrm{NO}_{2}$ exposure. $\mathrm{MoS}_{2}$ functionalization also improves the sensing response compared to that of CNTs alone. In addition, UV irradiation greatly promotes the recovery and reduces signal drift. 


\section{Temperature coefficient of resistance of CNT-WS 2 -cellulose}
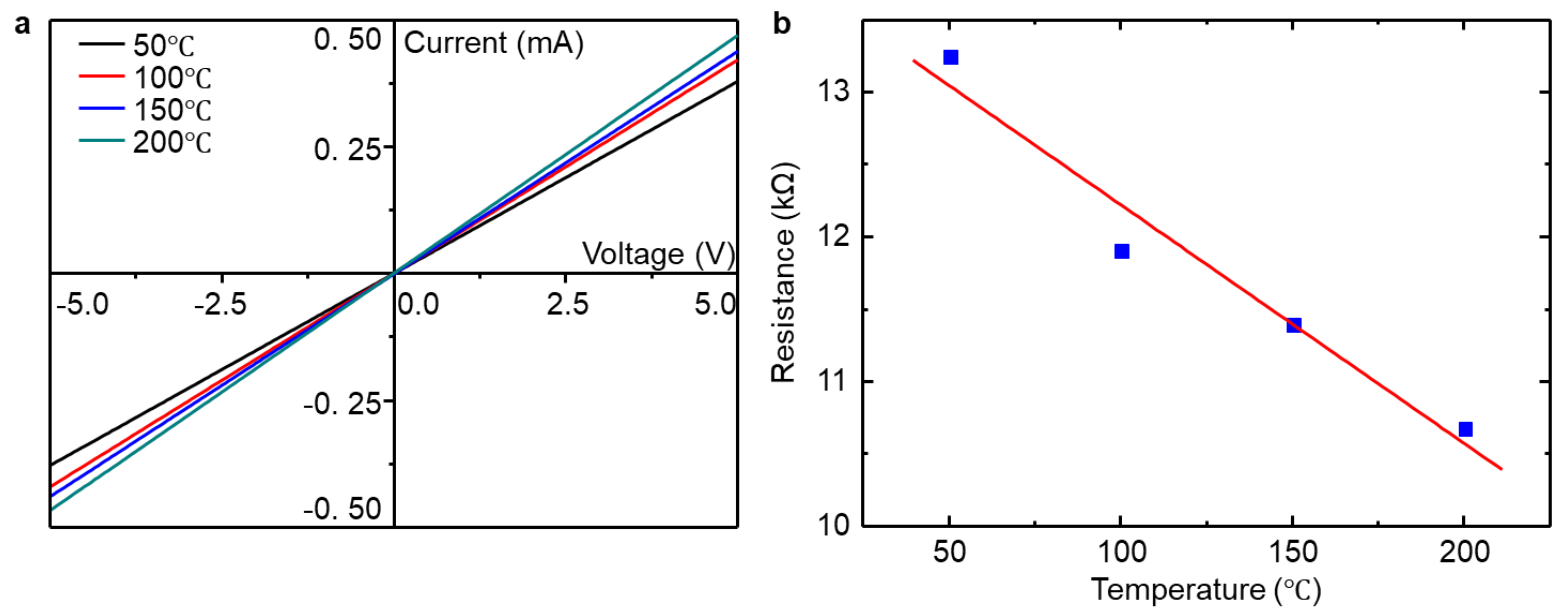

Figure S11. (a) Temperature dependent $I-V$ curves of CNT-WS $\mathrm{W}_{2}$-cellulose paper measured at 50, 100,150 , and $200^{\circ} \mathrm{C}$ in air. (b) Corresponding resistance change with respect to temperature and its temperature coefficient of resistance $\left(-0.24 \% /{ }^{\circ} \mathrm{C}\right)$. Increasing the temperature decreases the resistance, but the resistance change is much smaller than that under $\mathrm{NO}_{2}$ exposure. 


\section{Room-temperature $\mathrm{NO}_{2}$ sensing}
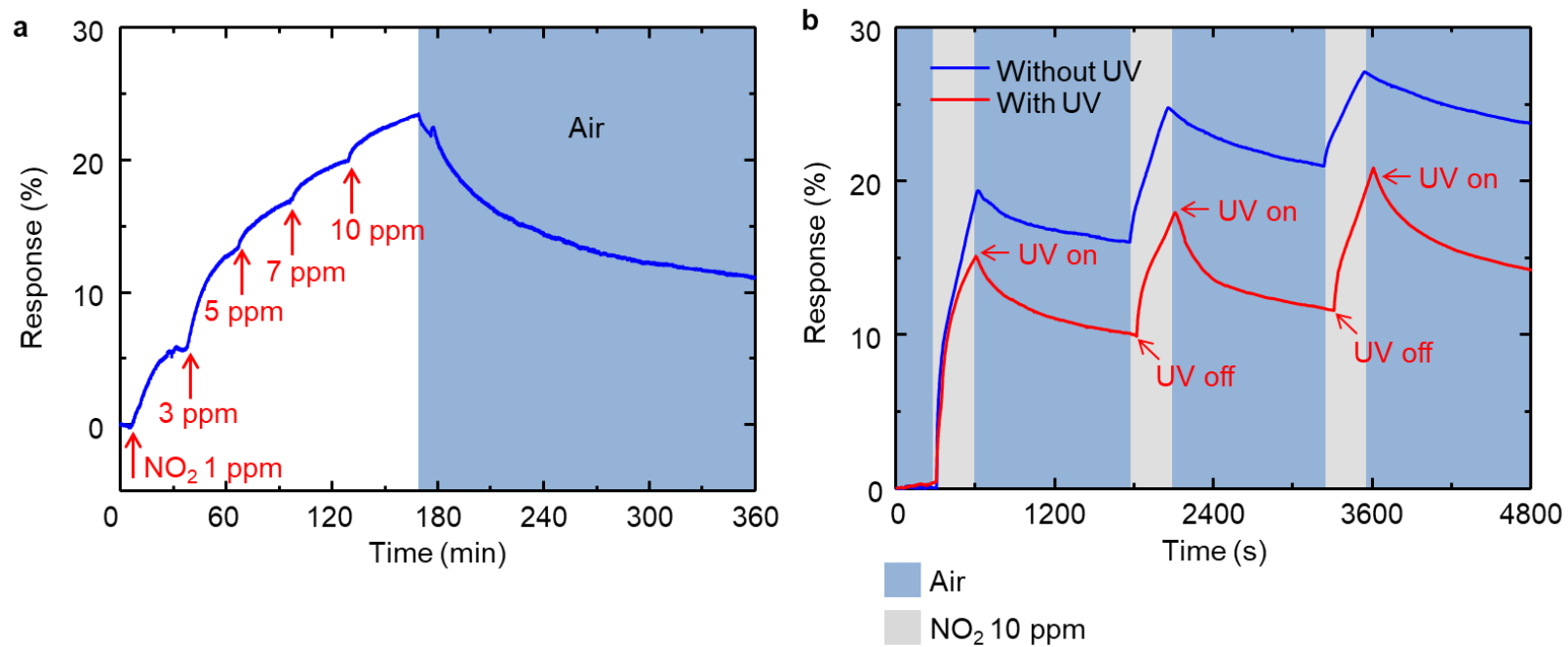

Figure S12. (a) $\mathrm{NO}_{2}$ sensing response of CNT- $\mathrm{WS}_{2}$-cellulose measured at room temperature with sequentially increasing $\mathrm{NO}_{2}$ concentration from 1 to $10 \mathrm{ppm}$. Although the response is slightly lower at room temperature than at $150^{\circ} \mathrm{C}$, the sensor can sensitively detect $\mathrm{NO}_{2}$ molecules. (b) Transient sensing response of CNT-WS 2 -cellulose with and without UV irradiation at room temperature. The UV irradiation facilitates the $\mathrm{NO}_{2}$ desorption and reduces the signal drift. 


\section{References}

(1) Philip, B.; Abraham, J. K.; Chandrasekhar, A.; Varadan, V. K. Cabon Nanotube/PMMA Composite Thin Films for Gas-Sensing Applications. Smart Mater. Struct. 2003, 12, 935 939.

(2) Lee, K.; Lee, J.-W.; Kim, S.-I.; Ju, B.-K. Single-Walled Carbon Nanotube/Nafion Composites as Methanol Sensors. Carbon 2011, 49, 787-792.

(3) Collins, P. G.; Bradley, K.; Ishigami, M.; Zettl, A. Extreme Oxygen Sensitivity of Electronic Properties of Carbon Nanotubes. Science 2000, 287, 1801-1804.

(4) Ovchinnikov, D.; Allain, A.; Huang, Y.-S.; Dumcenco, D.; Kis, A. Electrical Transport Properties of Single-Layer $\mathrm{WS}_{2}$. ACS Nano 2014, 8, 8174-8181.

(5) Ago, H.; Kugler, T.; Cacialli, F.; Salaneck, W. R.; Shaffer, M. S. P.; Windle, A. H.; Friend, R. H. Work Functions and Surface Functional Groups of Multiwall Carbon Nanotubes. J. Phys. Chem. B 1999, 103, 8116-8121.

(6) Kang, J.; Tongay, S.; Zhou, J.; Li, J.; Wu, J. Band Offsets and Heterostructures of TwoDimensional Semiconductors. Appl. Phys. Lett 2013, 102, 012111.

(7) Kong, J.; Franklin, N. R.; Zhou, C.; Chapline, M. G.; Peng, S.; Cho, K.; Dai, H. Nanotube Molecular Wires as Chemical Sensors. Science 2000, 287, 622-625.

(8) Valentini, L.; Armentano, I.; Kenny, J. M.; Cantalini, C.; Lozzi, L.; Santucci, S. Sensors for Sub-ppm $\mathrm{NO}_{2}$ Gas Detection Based on Carbon Nanotube Thin Films Appl. Phys. Lett 2003, 82, 961-963.

(9) Zhou, C.; Yang, W.; Zhu, H. Mechanism of Charge Transfer and its Impacts on FermiLevel Pinning for Gas Molecules Adsorbed on Monolayer $\mathrm{WS}_{2}$. J. Chem. Phys. 2015, $142,214704$.

(10) Wu, J.; Tao, K.; Zhang, J.; Guo, Y.; Miao, J.; Norford, L. K Chemically Functionalized 3D Graphene Hydrogel for High Performance Gas Sensing. J. Mater. Chem. A 2016, 4, 8130-8140.

(11) Wu, J.; Guo, Y.; Li, Zhong.; Wang, X.; Luo, Z.; Feng, S.; Du, C.; Chen, D.; Miao, J.; Norford, L. K. A 3D Chemically Modified Graphene Hydrogel for Fast, Highly Sensitive, and Selective Gas Sensor. Adv. Sci. 2017, 4, 1600319.

(12) Wu, J.; Feng, S.; Li, Z.; Tao, K.; Chu, J.; Miao, J.; Norford, L. K. Boosted Sensitivity of Graphene Gas Sensor via Nanoporous Thin Film Structures. Sens. Actuator B-Chem. 2018, 255, 1805-1813.

(13) Kang, J.; Huang, L.; Lin, Y.; Chen, L.; Zeng, Z.; Shen, L.; Chen, Q.; Shi, W. PencilTrace on Printed Silver Interdigitated Electrodes for Paper-Based $\mathrm{NO}_{2}$ Gas Sensors. Appl. Phys. Lett 2015, 106, 143101.

(14) Yang, G.; Lee, C.; Kim, J.; Ren, F.; Pearton, S. J. Flexible Graphene-Based Chemical Sensors on Paper Substrates. Phys. Chem. Chem. Phys. 2013, 15, 1798-1801.

(15) Mirica, K. A.; Azzarelli, J. M.; Weis, J. G.; Schnorr, J. M.; Swager, T. M. Rapid Prototyping of Carbon-Based Chemiresistive Gas Sensors on Paper. Proc. Natl. Acad. Sci. 2013, 110, E3265-E3270..

(16) Liu, H.; Li, M.; Voznyy, O.; Hu, L.; Fu, Q.; Zhou, D.; Xia, Z.; Sargent, E. H.; Tang, J. Physically Flexible, Rapid-Response Gas Sensor Based on Colloidal Quantum Dot Solids. Adv. Mater. 2014, 26, 2718-2724. 
(17) Zhao, Y.; Song, J.-G.; Ryu, G. H.; Ko, K. Y.; Woo, W. J.; Kim, Y.; Kim, D.; Lim, J. H.; Lee, S.; Lee, Z.; Park, J.; Kim, H. Low-Temperature Synthesis of 2D $\mathrm{MoS}_{2}$ on a Plastic Substrate for a Flexible Gas Sensor. Nanoscale 2018, 10, 9338-9345.

(18) Kim, Y. H.; Kim, S. J.; Kim, Y.-J.; Shim, Y.-S.; Kim, S. Y.; Hong, B. H.; Jang, H. W. Self-Activated Transparent All-Graphene Gas Sensor with Endurance to Humidity and Mechanical Bending. ACS Nano 2015, 9, 10453-10460.

(19) Cho, B.; Yoon, J.; Hahm, M. G.; Kim, D. H.; Kim, A. R.; Kahng, Y. H.; Park, S. W.; Lee, Y.-J.; Park, S.-G.; Kwon, J.-D.; Kim, C. S.; Song, M.; Jeong, Y.; Nam, K.-S.; Ko, H. C. Graphene-Based Gas Sensor: Metal Decoration Effect and Application to a Flexible Device. J. Mater. Chem. C 2014, 2, 5280-5285.

(20) Cho, B.; Yoon, J.; Lim, S. K.; Kim, A. R.; Kim, D.-H.; Park, S.-G.; Kwon, J.-D.; Lee, Y.J.; Lee, K.-H.; Lee, B. H.; Ko, H. C.; Hahm, M. G. Chemical Sensing of 2D Graphene/ $\mathrm{MoS}_{2}$ Heterostructure device. ACS Appl. Mater. Interfaces 2015, 7, 1677516780.

(21) Yaqoob, U.; Uddin, A. S. M. I.; Chung, G.-S. A High-Performance Flexible $\mathrm{NO}_{2}$ Sensor Based on $\mathrm{WO}_{3}$ NPs Decorated on MWCNTs and RGO Hybrids on PI/PET Substrates. Sens. Actuator B-Chem. 2016, 224, 738-746.

(22) Huang, L.; Wang, Z.; Zhang, J.; Pu, J.; Lin, Y.; Xu, S.; Shen, L.; Chen, Q.; Shi, W. Fully Printed, Rapid-Response Sensors Based on Chemically Modified Graphene for Detecting $\mathrm{NO}_{2}$ at Room Temperature. ACS Appl. Mater. Interfaces 2014, 6, 7426-7433.

(23) Su, P.-G.; Lee, C.-T.; Chou, C.-Y.; Cheng, K.-H.; Chuang, Y.-S. Fabrication of Flexible $\mathrm{NO}_{2}$ Sensors by Layer-by-Layer Self-Assembly of Multi-Walled Carbon Nanotubes and their Gas Sensing Properties. Sens. Actuator B-Chem. 2009, 139, 488-493.

(24) He, Q.; Zeng, Z.; Yin, Z.; Li, H.; Wu, S.; Huang, X.; Zhang, H. Fabrication of Flexible $\mathrm{MoS}_{2}$ Thin-Film Transistor Arrays for Practical Gas-Sensing Applications. Small 2012, 8 , 2994.

(25) Lee, C.; Ahn, J.; Lee, K. B.; Kim, D.; Kim, J. Graphene-Based Flexible $\mathrm{NO}_{2}$ Chemical Sensors. Thin Solid Films 2012, 520, 5459-5462.

(26) Su, P.-G.; Shieh, H.-C. Flexible $\mathrm{NO}_{2}$ Sensors Fabricated Layer-by-Layer Covalent Anchoring and In Situ Reduction of Graphene Oxide. Sens. Actuator B-Chem. 2014, 190, 865-872.

(27) Lewis, J. Material Challenge for Flexible Organic Devices. Materials Today 2006, 9, 3845. 